\title{
Pressure-dependence of the phase transitions and thermal expansion in zirconium and hafnium pyrovanadate
}

\author{
Leighanne C. Gallington ${ }^{\mathrm{a}, 1}$, Brett R. Hester ${ }^{\mathrm{a}}$, Benjamin S. Kaplan ${ }^{\mathrm{a}}$, Angus P. Wilkinson ${ }^{\mathrm{a}, \mathrm{b}, *}$ \\ ${ }^{a}$ School of Chemistry and Biochemistry, Georgia Institute of Technology, Atlanta, Georgia 30332-0400 \\ ${ }^{b}$ School of Materials Science and Engineering, Georgia Institute of Technology, Atlanta, Georgia 30332-0245
}

\begin{abstract}
Low or negative thermal expansion (NTE) has been previously observed in members of the $\mathrm{ZrP}_{2} \mathrm{O}_{7}$ family at temperatures higher than their order-disorder phase transitions. The thermoelastic properties and phase behavior of the low temperature superstructure and high temperature negative thermal expansion phases of $\mathrm{ZrV}_{2} \mathrm{O}_{7}$ and $\mathrm{HfV}_{2} \mathrm{O}_{7}$ were explored via in situ variable temperature/pressure powder x-ray diffraction measurements. The phase transition temperatures of $\mathrm{ZrV}_{2} \mathrm{O}_{7}$ and $\mathrm{HfV}_{2} \mathrm{O}_{7}$ exhibited a very strong dependence on pressure ( $\left.700 \mathrm{~K} \cdot \mathrm{GPa}\right)$, with moderate compression suppressing the formation of their NTE phases below $513 \mathrm{~K}$. Compression also reduced the magnitude of the coefficients of thermal expansion in both the positive and negative thermal expansion phases. Additionally, the high temperature NTE phase of $\mathrm{ZrV}_{2} \mathrm{O}_{7}$ was found to be twice as stiff as the low temperature positive thermal expansion superstructure (24 and 12 GPa respectively).
\end{abstract}

Keywords: thermal expansion, phase transitions, thermoelastic properties, zirconium pyrovanadate

\section{Introduction}

Negative thermal expansion (NTE) materials continue to receive considerable attention [1-3] due to fundamental interest in this unusual phenomenon and their potential application compensating for the positive thermal expansion (PTE) of other materials. Their use in composites $[4-10]$ to provide enhanced dimensional stability, or an expansion match with other components, has been examined. However, thermal expansion mismatch between NTE and PTE materials in composites gives rise to internal stresses, which can be detrimental to the performance of the composite [9-13] as many NTE framework solids undergo phase transitions or changes in properties at low pressures. The combination of rich behavior upon modest compression and stresses arising from processing or thermal expansion mismatch motivates our studies of NTE materials under pressure [14-24].

While negative thermal expansion has been observed in a number of materials, many of them either exhibit NTE over a limited temperature range [25-27] or display highly anisotropic NTE [28-31]. Isotropic NTE over wide temperature range is especially interesting and has been observed in $\mathrm{ZrW}_{2} \mathrm{O}_{8}$ [32], $\mathrm{ScF}_{3}$ [33], and other materials in these structural families $[13,18,19,32,34,35]$. Isotropic

\footnotetext{
* Corresponding author

Email address: angus.wilkinson@chemistry.gatech.edu (Angus P. Wilkinson)

${ }^{1}$ Current Address: X-ray Science Division, Advanced Photon Source, Argonne National Laboratory, Argonne, Illinois 60439
}

negative thermal expansion is also seen for some compositions in the $\mathrm{ZrP}_{2} \mathrm{O}_{7}$ family, but only at above ambient temperature [36-40]. $\mathrm{ZrP}_{2} \mathrm{O}_{7}$ itself does not exhibit NTE, but its thermal expansion dramatically decreases after undergoing a symmetry-increasing transition on heating [36, 41]. $\mathrm{ZrV}_{2} \mathrm{O}_{7}$ exhibits $\mathrm{NTE}$ above $\sim 373 \mathrm{~K}$ at ambient pressure, where it has a $\sim 8.8 \AA$ cubic unit cell $[36,42]$. Its low temperature (LT) form, which is a cubic $3 \times 3 \times 3$ superstructure of the high temperature (HT) NTE phase with a more ordered arrangement of $\mathrm{V}_{2} \mathrm{O}_{7}$ units [37, 43, 44], exhibits strong positive thermal expansion $\left(\alpha_{l, 300 K}=24\right.$ $\mathrm{ppm} \cdot \mathrm{K}^{-1}$ ) [45]. A drawing of the subcell is shown in Figure 1. Heating the low temperature form leads to two phase transitions: the first gives rise to an incommensurate structure displaying PTE; the second leads to the high temperature NTE phase. Both occur within a narrow temperature range $(\sim 45 \mathrm{~K})$ and are associated with large volume changes.

The behavior of $\mathrm{ZrV}_{2} \mathrm{O}_{7}$ under pressure has previously been studied at ambient temperature [46, 47]. On compression to $1.38 \mathrm{GPa}, \mathrm{ZrV}_{2} \mathrm{O}_{7}$ transforms to a phase with orthorhombic symmetry, and above $4 \mathrm{GPa}$ it amorphizes $[46,47]$. The low temperature form of cubic $\mathrm{ZrV}_{2} \mathrm{O}_{7}\left(\kappa_{T}\right.$ $=17 \mathrm{GPa}$ ) was reported to be much softer than other members of the $\mathrm{ZrP}_{2} \mathrm{O}_{7}$ family at ambient temperature $\left(\kappa_{T}\left(\mathrm{ZrP}_{2} \mathrm{O}_{7}, \mathrm{TiP}_{2} \mathrm{O}_{7}\right) \simeq 40 \mathrm{GPa}\right)$ [46], and is much softer than previously studied $\mathrm{ZrW}_{2} \mathrm{O}_{8}$ family members $\left(\kappa_{T}=\right.$ 41-74 GPa) $[14,15,34,48,49]$. However, $\mathrm{ZrV}_{2} \mathrm{O}_{7}$ only adopts a structure that supports NTE at above room temperature, and no high pressure studies have been performed on this phase. In this paper, the phase behavior, 


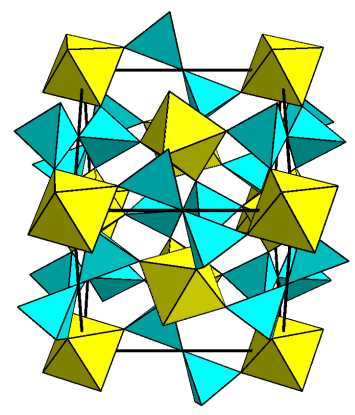

Figure 1: Structure of the high temperature (NTE) phase of $\mathrm{ZrV}_{2} \mathrm{O}_{7}$. The $\mathrm{ZrO}_{6}$ octahedra and $\mathrm{VO}_{4}$ tetrahedra are yellow and blue respectively.

thermal expansion and elastic properties of $\mathrm{ZrV}_{2} \mathrm{O}_{7}$ and $\mathrm{HfV}_{2} \mathrm{O}_{7}$ are examined at pressures/temperatures between 0 - $310 \mathrm{MPa}$ and 300 - $525 \mathrm{~K}$; a regimen which is well matched to likely applications for NTE solids.

\section{Methods}

\subsection{Syntheses}

Zirconium and hafnium pyrovanadate were synthesized via a previously described solid-state route [36]. Zirconyl chloride hydrate (Alfa Aesar, Ward Hill, MA) and hafnium oxychloride hydrate (Alfa Aesar, Ward Hill, MA) were mixed with $\mathrm{a} \geq 5 \%$ stoichoimetric excess of ammonium metavanadate (Fisher Scientific, Waltham, MA). Samples were heated at $1023 \mathrm{~K}$ in $\sim 24 \mathrm{hr}$ increments, sand-quenched, and reground. Heat treatments were repeated until the samples were essentially phase pure. Laboratory x-ray powder diffraction was used to verify the identity and purity of the final products.

\subsection{Sample Environment and X-ray Data Collection}

High pressure diffraction patterns were collected at beam line 11-ID-B of the Advanced Photon Source using 58.65 $\mathrm{keV}(0.2114 \AA)$ x-rays, a sample to detector distances of $\sim 87 \mathrm{~cm}$ and a PerkinElmer amorphous silicon 2D detector. A previously described variable temperature/pressure sample environment was used to access temperatures between 298 and $513 \mathrm{~K}$ and pressures upto $310 \mathrm{MPa}[14,15$, 50]. Two different data collection schemes were utilized. In the first, samples were initially compressed to $310 \mathrm{MPa}$ in $103 \mathrm{MPa}$ increments, decompressed to $257 \mathrm{MPa}$, then decompressed to $52 \mathrm{MPa}$ in $103 \mathrm{MPa}$ increments. In the second, samples were initially compressed to $155 \mathrm{MPa}$ in 52 $\mathrm{MPa}$ increments, decompressed to $129 \mathrm{MPa}$, then decompressed to $26 \mathrm{MPa}$ in $52 \mathrm{MPa}$ increments. In both cases, samples were subsequently heated to the next temperature, where the same compression/decompression scheme was used.

Ambient pressure/variable temperature x-ray scattering data were also collected at beamline 11-ID-B of the

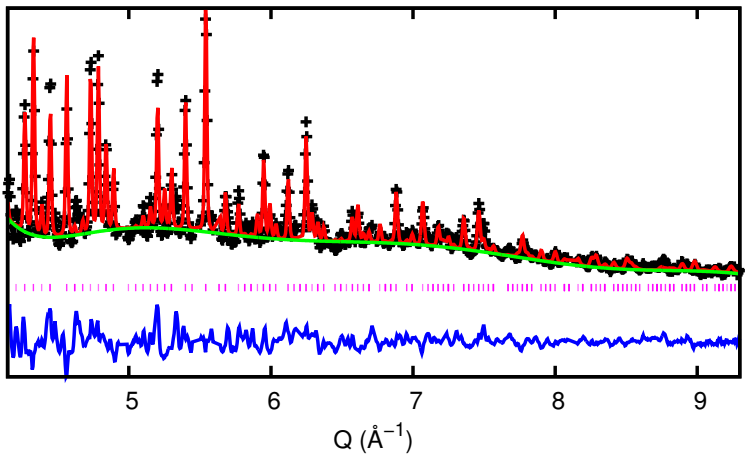

Figure 2: Rietveld fit using the high temperature $\mathrm{Pa} \overline{3}$ model for $\mathrm{ZrV}_{2} \mathrm{O}_{7}$ XRD pattern collected at room temperature and $310 \mathrm{MPa}$.

Advanced Photon Source using $58.26 \mathrm{keV}(0.2128 \AA)$ xrays. Powdered samples were loaded into Kapton capillaries. Temperatures between 100 and $500 \mathrm{~K}$ were accessed using an Oxford Cryosystems Cryostream. Samples were initially cooled to $100 \mathrm{~K}$, then heated to $500 \mathrm{~K}$ at 1 $\mathrm{K} \cdot \min ^{-1}$.

\subsection{Diffraction Data Analysis}

Rietveld analysis of the data [51-53] was performed after reduction of images to one-dimensional patterns $[50$, 54, 55]. A structural model for the high temperature phase, taken from Khosrovani et al. [37], was used in these analyses. Lattice constants were obtained from refinements where a background function (10 term shifted Chebyshev), scale factor, unit cell edge, 4 profile coefficients, and isotropic atomic displacement parameters for $\mathrm{Zr} / \mathrm{Hf}$ and $\mathrm{V}$ were varied. Refinement of atomic positions and oxygen atomic displacement parameters could not be performed using the available data. Rietveld analyses of data recorded in this sample environment can be problematic due to poor sampling statistics associated with the small volume of illuminated sample, high background levels due to the significant amount of material in the beam path, and partial shadowing at low $\mathrm{Q}$ by the internal beam stop. The resolution of the data is also limited by the size and pixel size of the detector. A representative fit using the high temperature subcell model for $\mathrm{ZrV}_{2} \mathrm{O}_{7}$ is shown in Figure 2. Analyses using the much more complex room temperature superstructure were unsuccessful, due to the limited quality of the available data. Previous studies have shown that the supercell $\rightarrow$ incommensurate and incommensurate $\rightarrow$ subcell transitions are associated with large increases in lattice constant, and that NTE occurs only in the high temperature phase. The pressures and temperatures at which these phase transitions occur were estimated based on steep changes in volume and the onset of NTE [36-38, 42, 45]. 


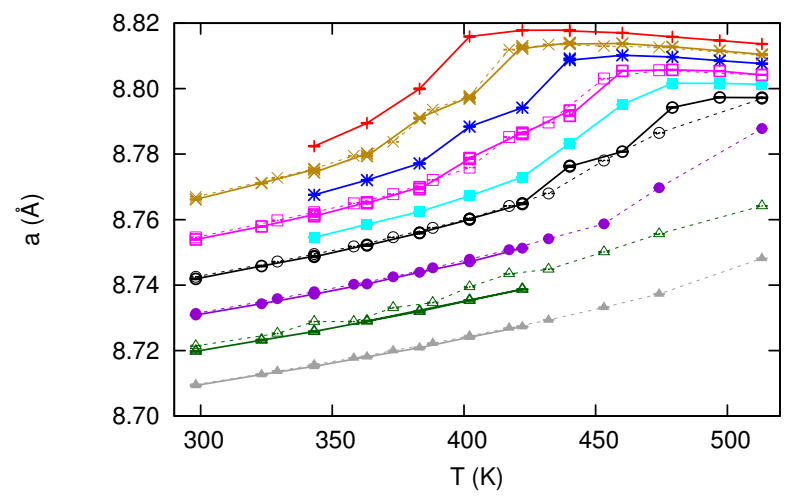

Figure 3: Variation of lattice parameters for $\mathrm{ZrV}_{2} \mathrm{O}_{7}$ with temperature at different pressures: $26 \mathrm{MPa}$ (red), $52 \mathrm{MPa}$ (goldenrod), 78 MPa (blue), $103 \mathrm{MPa}$ (magenta), $129 \mathrm{MPa}$ (cyan), $155 \mathrm{MPa}$ (black), $206 \mathrm{MPa}$ (purple), $258 \mathrm{MPa}$ (dark-green), and $310 \mathrm{MPa}$ (gray).

\section{Results and Discussion}

\subsection{Pressure Dependence of the Phase Transitions}

The dependence of the lattice parameters for $\mathrm{ZrV}_{2} \mathrm{O}_{7}$ on temperature at different pressures are shown in Figure 3 and in Supporting Information Tables I-III. The steep increases in volume associated with the supercell $\rightarrow$ incommensurate and incommensurate $\rightarrow$ subcell transitions are both shifted to significantly higher temperatures as the pressure is increased. The onset of NTE was shifted by $\sim 38 \mathrm{~K}$ in $\mathrm{ZrV}_{2} \mathrm{O}_{7}$ and $\sim 36 \mathrm{~K}$ in $\mathrm{HfV}_{2} \mathrm{O}_{7}$ upon increasing sample pressure from 52 to $103 \mathrm{MPa}$ and later measurements on $\mathrm{ZrV}_{2} \mathrm{O}_{7}$, which included additional temperature points between 473 and $513 \mathrm{~K}$, revealed that at $155 \mathrm{MPa}$, the onset of NTE occurs at $497 \mathrm{~K}$, an increase of $\sim 80$ $\mathrm{K}$ above the transition temperature at $52 \mathrm{MPa}$. Large changes in the supercell $\rightarrow$ incommensurate phase transition temperature are also observed for both $\mathrm{ZrV}_{2} \mathrm{O}_{7}$ and $\mathrm{HfV}_{2} \mathrm{O}_{7}$ on compression.

The phase behavior of $\mathrm{ZrV}_{2} \mathrm{O}_{7}$ upon compression and heating is summarized in Figure 4. The phase at each point in pressure temperature space was assigned based on the variation of the lattice constant with temperature at each pressure as shown in Figure 3: points below the first large volume change at a given pressure were assigned to the low temperature (LT) phase; points between the first and second large volume changes were assigned to the incommensurate phase; points above the second large volume change, where the onset of NTE was observed, were assigned to the high temperature (HT) NTE phase. Supercell/incommensurate and incommensurate/subcell phase boundaries were drawn to separate the phases. The slopes of the phase boundaries $\left(\frac{d T}{d P}\right)_{L T \rightarrow \text { inc. }}$ and $\left(\frac{d T}{d P}\right)_{\text {inc. } \rightarrow H T}$ were estimated to be $\sim 640 \mathrm{~K} \cdot \mathrm{GPa}^{-1}$ and $\sim 740 \mathrm{~K} \cdot \mathrm{GPa}^{-1}$ respectively. These transitions are approximately an order of magnitude more pressure-sensitive than those observed in many materials, including perovskites $(\sim 10-80$ $\left.\mathrm{K} \cdot \mathrm{GPa}^{-1}\right)[56]$; however, they are comparable to those observed in $\mathrm{ScF}_{3}$ and $\mathrm{Sc}_{1-x} \mathrm{Al}_{x} \mathrm{~F}_{3}\left(400-500 \mathrm{~K} \cdot \mathrm{GPa}^{-1}\right)$, which

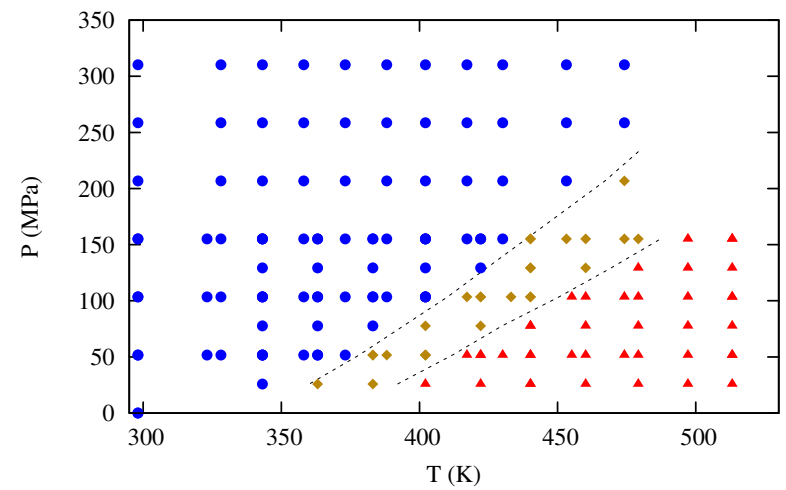

Figure 4: Pressure-temperature phase diagram of $\mathrm{ZrV}_{2} \mathrm{O}_{7}$. The LT phase is indicated by blue circles, incommensurate by goldenrod diamonds, and HT by red triangles.

are essentially A-site vacant perovskites [19, 33].

For first order transitions, the slope of the pressure temperature phase boundary is related to the volume and entropy changes associated with the transition by the Clapeyron equation [57]:

$$
\frac{d P}{d T}=\frac{\Delta_{t r s} \bar{S}}{\Delta_{t r s} \bar{V}}
$$

If we assume that this equation is approximately applicable to our system, we can use molar volume changes estimated from our variable temperature XRD measurements, conducted at ambient pressure between 100 and $500 \mathrm{~K}$ (Figure 5 and Supporting Information Table IV), along with previously reported calorimetry-derived $\Delta_{t r s} S$ for the two phase transitions $(0.41 \pm 0.01 \mathrm{~J} /(\mathrm{K} \cdot \mathrm{mol})$ and $0.73 \pm 0.05 \mathrm{~J} /(\mathrm{K} \cdot \mathrm{mol})$ respectively) [45] to independently estimate the phase boundary slope for each transition. The change in molar volume for each transition was taken to be the difference between the beginning and end of each steep increase in volume. This results in estimates for $\left(\frac{d T}{d P}\right)$, of $\sim 740 \mathrm{~K} \cdot \mathrm{GPa}^{-1}$ for the supercell $\rightarrow$ incommensurate and $\sim 590 \mathrm{~K} \cdot \mathrm{GPa}^{-1}$ for the incommensurate $\rightarrow$ subcell transitions, which are remarkably close to those determined directly from the high pressure measurements.

\subsection{Phase-Dependent Variation in Compressibility with Temperature}

The isothermal bulk modulus is defined in the equation below [57]:

$$
\kappa_{T} \equiv-\left(\frac{\partial P}{\partial \ln V}\right)_{T}
$$

Linear regression to $\ln$ (Volume) versus pressure data was used to determine bulk moduli (Supporting Information Figure 2). Bulk moduli for $\mathrm{ZrV}_{2} \mathrm{O}_{7}$ and $\mathrm{HfV}_{2} \mathrm{O}_{7}$ at temperatures between room temperature and $513 \mathrm{~K}$ are shown in Figure 6 and Supporting Information Tables V-VII. Average room temperature bulk moduli of $\mathrm{ZrV}_{2} \mathrm{O}_{7}$ and $\mathrm{HfV}_{2} \mathrm{O}_{7}$ derived from our measurements are lower than 


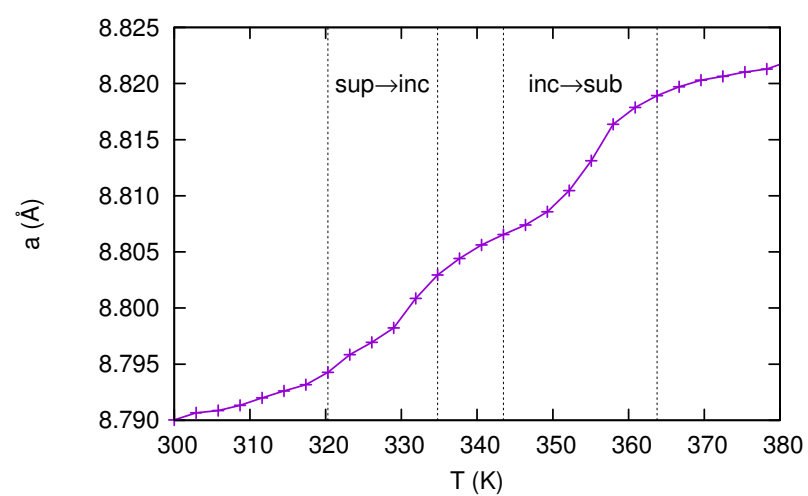

Figure 5: Lattice parameters of $\mathrm{ZrV}_{2} \mathrm{O}_{7}$ between 300 and $380 \mathrm{~K}$ obtained from ambient pressure XRD measurements.

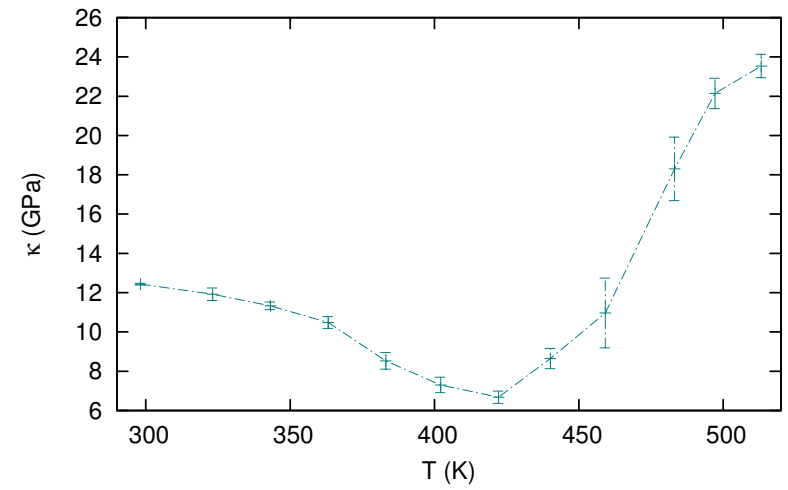

Figure 6: Bulk moduli of $\mathrm{ZrV}_{2} \mathrm{O}_{7}$ calculated between 25 and 155 MPa. that previously reported for $\mathrm{ZrV}_{2} \mathrm{O}_{7}(17 \mathrm{GPa})$ [46]. As a substantially broader pressure range $(0-1.38 \mathrm{GPa})$ was used to determine the previously reported ambient temperature bulk modulus [46] and pressure-induced stiffening is a common phenomenon in solids $[58,59]$, a more relevant comparison might be obtained from recalculating the bulk modulus using data that lies within a comparable pressure range. Recalculation of the bulk modulus using only data between 80 and $290 \mathrm{MPa}$ [46], resulted in a 50\% drop in magnitude to $8.7 \mathrm{GPa}$.

Upon heating, the bulk modulus for $\mathrm{ZrV}_{2} \mathrm{O}_{7}\left(\kappa_{25-155 M P a}\right.$ drops $\sim 46 \%$ in the regime where the incommensurate phase is present. A comparable softening is observed in $\mathrm{HfV}_{2} \mathrm{O}_{7}$. Upon heating to $513 \mathrm{~K}$, where the NTE phase is present, the stiffness of both materials increases by over $100 \%$ relative to room temperature. The twofold increase in stiffness observed upon heating was not anticipated, as most materials soften upon heating [60-62]. In previous studies of open framework NTE materials, significant softening upon heating was observed in $\mathrm{ZrW}_{2} \mathrm{O}_{8}$ and $\mathrm{HfW}_{2} \mathrm{O}_{8}$ $[14,15]$, while slight stiffening occurred in $\mathrm{ZrMo}_{2} \mathrm{O}_{8}$ [14], $\mathrm{Y}_{x} \mathrm{Sc}_{1-x} \mathrm{~F}_{3}$ [20], and $\mathrm{Al}_{x} \mathrm{Sc}_{1-x} \mathrm{~F}_{3}$ [19]. The cause of the increase in elastic stiffness of the HT phase as compared to the LT structure is unknown, but may be due to differences in the orientational ordering of $\mathrm{V}_{2} \mathrm{O}_{7}$ units between the two phases.

\subsection{Pressure-Induced Reductions in Coefficient of Ther- mal Expansion}

The temperature dependence of the bulk modulus and the pressure dependence of the coefficient of thermal expansion (CTE) are related as described in Equation 3 [60]:

$$
\left(\frac{\partial \alpha}{\partial P}\right)_{T}=\frac{1}{\kappa_{T}^{2}}\left(\frac{\partial \kappa_{T}}{\partial T}\right)_{P}
$$

The pressure dependence of the linear CTEs of $\mathrm{ZrV}_{2} \mathrm{O}_{7}$ and $\mathrm{HfV}_{2} \mathrm{O}_{7}$ are shown in Figure 7 and Supporting Information Figure 1. The CTE of the LT phase of $\mathrm{ZrV}_{2} \mathrm{O}_{7}$ at $52 \mathrm{MPa}(24 \mathrm{ppm} / \mathrm{K})$ matches the ambient pressure CTE reported in previous literature [45]; the high temperature $\mathrm{CTE}$ at $26 \mathrm{MPa}(-7.2 \mathrm{ppm} / \mathrm{K})$ is also relatively close to the previously reported ambient pressure CTE $(-6.8 \mathrm{ppm} / \mathrm{K})$ [42]. A substantial reduction in the magnitude of both CTEs was observed upon compression. The reduction in CTE appears to be a byproduct of the extremely pressuresensitive phase transitions that occur in $\mathrm{ZrV}_{2} \mathrm{O}_{7}$. The CTE of the HT phase becomes less negative $(\sim 85 \%)$ upon compression, as increasing the pressure eventually drives $\mathrm{ZrV}_{2} \mathrm{O}_{7}$ back through the subcell $\rightarrow$ incommensurate transition, which is associated with both large changes in volume and positive thermal expansion. Similarly, since the supercell $\rightarrow$ incommensurate temperature increases with pressure, compression of the LT phase forces $\mathrm{ZrV}_{2} \mathrm{O}_{7}$ further away from this transition and the large increase in volume associated with it, resulting in a $\sim 35 \%$ drop in CTE between 52 and $310 \mathrm{MPa}$. The reduction in the CTE 

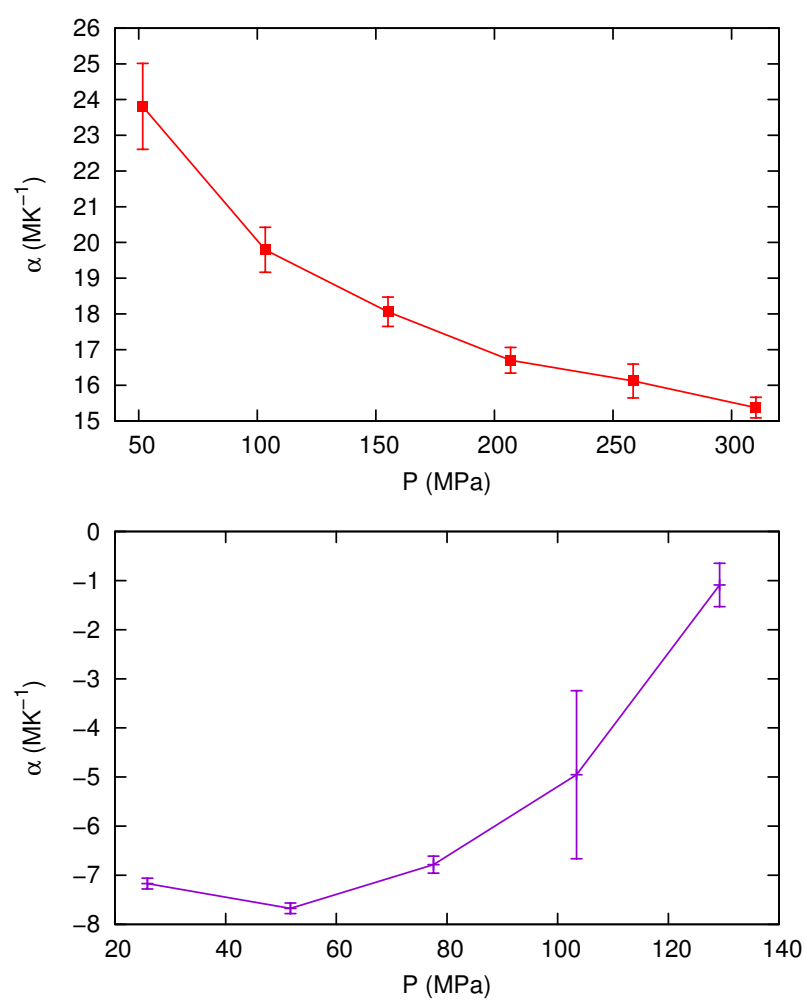

Figure 7: Variation of $\mathrm{ZrV}_{2} \mathrm{O}_{7}$ linear CTEs with pressure. $\mathrm{ZrV}_{2} \mathrm{O}_{7}$ CTEs were calculated between 298 and $363 \mathrm{~K}$ for the LT phase (top) and $479-513 \mathrm{~K}$ for the HT phase (bottom).

of the supercell phase upon compression, $9 \mathrm{ppm} / \mathrm{K}$, is even larger than the change in CTE observed in $\mathrm{HfW}_{2} \mathrm{O}_{8}$ over a broader pressure range [15]. In $\mathrm{HfV}_{2} \mathrm{O}_{7}$, noticeable hysteresis in volume upon compression and decompression at room temperature resulted in erroneously lowered supercell CTEs at pressures measured on decompression (Supporting Information Figures 1-2). While overall, a noticeable reduction in the CTE was observed upon compression much like $\mathrm{ZrV}_{2} \mathrm{O}_{7}$, quantitative statements about the extent of this reduction cannot be made definitely due to the large errors associated with these CTEs.

\section{Conclusions}

Variable temperature/pressure measurements revealed that temperatures at which the supercell $\rightarrow$ incommensurate and incommensurate $\rightarrow$ subcell transitions occur in $\mathrm{ZrV}_{2} \mathrm{O}_{7}$ and $\mathrm{HfV}_{2} \mathrm{O}_{7}$ are strongly pressure-dependent. The pressure-sensitivity observed was even more pronounced in these materials than in other open framework materials such as $\mathrm{ScF}_{3}[19,33]$. The CTEs of both the HT and LT phases were strongly pressure-dependent. On heating, elastic softening was observed at temperatures close to the transition to the incommensurate phase prior to considerable stiffening in the HT phase. However, unlike $\mathrm{ZrW}_{2} \mathrm{O}_{8}$ and $\mathrm{HfW}_{2} \mathrm{O}_{8}[14,15]$, compression elevates transition temperatures. The drop in magnitude of the CTE on compression of the LT phase arises primarily because the LT $\rightarrow$ incommensurate transition, and its associated volume increase, occurs at higher temperatures. The precise origin of the considerable stiffening seen on going from the LT to HT structures is unknown, but it is presumably associated with orientational disordering within the $\mathrm{V}_{2} \mathrm{O}_{7}$ units.

\section{Acknowledgements}

This research used resources of the Advanced Photon Source, a U.S. Department of Energy (DOE) Office of Science User Facility operated for the DOE Office of Science by Argonne National Laboratory under Contract No. DE-AC02-06CH11357. Some funding was provided by the Georgia Institute of Technology. We are grateful for the assistance of Cody Morelock, Justin Hancock, and Luiza Rosa de Araujo.

\section{References}

[1] C. P. Romao, K. J. Miller, C. A. Whitman, M. A. White, B. A. Marinkovic, Negative Thermal Expansion (Thermomiotic) Materials, Vol. 4, Elsevier, Oxford, 2013, pp. 128-151.

[2] C. Lind, Materials 5 (6) (2012) 1125-1154.

[3] J. Chen, L. Hu, X. Xing, Negative thermal expansion in functional materials: controllable thermal expansion by chemical modifications, Chem. Soc. Rev. 44 (2015) 3522-3567.

[4] E. Della Gaspera, R. Tucker, K. Star, E. H. Lan, Y. S. Ju, B. Dunn, ACS Appl. Mater. Interfaces 5 (21) (2013) 10966-74.

[5] K. Takenaka, Science and Technology of Advanced Materials 13 (1) (2012) 013001.

[6] C. Lind, M. R. Coleman, L. C. Kozy, G. R. Sharma, Phys. Status Solidi. B 248 (1) (2011) 123-129.

[7] A. Chandra, W. H. Meyer, A. Best, A. Hanewald, G. Wegner, Macromol. Mater. Eng. 292 (3) (2007) 295-301.

[8] P. Lommens, C. De Meyer, E. Bruneel, K. De Buysser, I. Van Driessche, S. Hoste, Journal of The European Ceramic Society 25 (16) (2005) 3605-3610.

[9] D. K. Balch, D. C. Dunand, Metall. Mater. Trans. A 35A (2004) 1159-1165.

[10] S. Yilmaz, J. Phys.: Condens. Matter 14 (2002) 365-375.

[11] Y. Wu, M. L. Wang, Z. Chen, N. H. Ma, H. W. Wang, Journal of Materials Science 48 (7) (2013) 2928-2933.

[12] S. Yilmaz, D. C. Dunand, Compos. Sci. Technol. 64 (12) (2004) 1895-1898.

[13] C. R. Morelock, M. R. Suchomel, A. P. Wilkinson, J. Appl. Crystallogr. 46 (3).

[14] L. C. Gallington, K. W. Chapman, C. R. Morelock, P. J. Chupas, A. P. Wilkinson, Phys. Chem. Chem. Phys. 15 (45) (2013) 19665-19672.

[15] L. C. Gallington, K. W. Chapman, C. R. Morelock, P. J. Chupas, A. P. Wilkinson, J. Appl. Phys. 115 (5) (2014) 053512.

[16] T. Varga, A. P. Wilkinson, A. C. Jupe, C. Lind, W. A. Bassett, C.-S. Zha, Phys. Rev. B 72 (2005) 024117-(1-10).

[17] T. Varga, A. P. Wilkinson, C. Lind, W. A. Basset, C.-S. Zha, Solid State Commun. 135 (2005) 739-744.

[18] J. C. Hancock, K. W. Chapman, G. J. Halder, C. R. Morelock, B. S. Kaplan, L. C. Gallington, A. Bongiorno, C. Han, S. Zhou, A. P. Wilkinson, Chem. Mater. 27 (11) (2015) 3912-3918.

[19] C. R. Morelock, L. C. Gallington, A. P. Wilkinson, J. Solid State Chem. 222 (2015) 96-102.

[20] C. R. Morelock, B. K. Greve, L. C. Gallington, K. W. Chapman, A. P. Wilkinson, J. Appl. Phys. 114 (21) (2013) 213501.

[21] M. Cetinkol, A. P. Wilkinson, C. Lind, Phys. Rev. B 79 (22) (2009) 224118-10. 
[22] T. Varga, A. P. Wilkinson, C. Lind, W. A. Bassett, C.-S. Zha, Phys. Rev. B 71 (2005) 214106 (1-8).

[23] T. Varga, A. P. Wilkinson, C. Lind, W. A. Bassett, C.-S. Zha, J. Phys.: Condens. Matter 17 (2005) 4271-4283.

[24] T. Varga, A. P. Wilkinson, J. D. Jorgensen, S. Short, Solid State Sciences 8 (2006) 289-295.

[25] T. Chatterji, T. C. Hansen, M. Brunelli, P. F. Henry, Appl. Phys. Lett. 94 (24) (2009) 241902.

[26] M. Azuma, W.-t. Chen, H. Seki, M. Czapski, S. Olga, K. Oka, M. Mizumaki, T. Watanuki, N. Ishimatsu, N. Kawamura, S. Ishiwata, M. G. Tucker, Y. Shimakawa, J. P. Attfield, Nat. Commun. 2 (2011) 347.

[27] Y. W. Long, N. Hayashi, T. Saito, M. Azuma, S. Muranaka, Y. Shimakawa, Nature 458 (7234) (2009) 60-U3.

[28] A. L. Goodwin, M. Calleja, M. J. Conterio, M. T. Dove, J. S. O. Evans, D. A. Keen, L. Peters, M. G. Tucker, Science 319 (5864) (2008) 794-797.

[29] J. S. O. Evans, T. A. Mary, A. W. Sleight, J. Solid State Chem. 137 (1998) 148-160.

[30] J. S. O. Evans, T. A. Mary, A. W. Sleight, J. Solid State Chem. 133 (1997) 580-583.

[31] G. Lenain, H. A. McKinstry, S. Y. Limaye, A. Woodward, Mat. Res. Bull. 19 (1984) 1451-1456.

[32] J. S. O. Evans, T. A. Mary, T. Vogt, M. A. Subramanian, A. W. Sleight, Chem. Mater. 8 (1996) 2809-2823.

[33] B. K. Greve, K. L. Martin, P. L. Lee, P. J. Chupas, K. W. Chapman, A. P. Wilkinson, J. Am. Chem. Soc. 132 (44) (2010) 15496-15498.

[34] C. Lind, A. P. Wilkinson, Z. Hu, S. Short, J. D. Jorgensen, Chem. Mater. 10 (1998) 2335-2337.

[35] C. R. Morelock, L. C. Gallington, A. P. Wilkinson, Chem. Mater. 26 (5) (2014) 1936-1940.

[36] V. Korthuis, N. Khosrovani, A. W. Sleight, N. Roberts, R. Dupree, W. W. Warren, Chem. Mater. 7 (1995) 412-417.

[37] N. Khosrovani, A. Sleight, T. Vogt, J. Solid State Chem. 132 (1997) 355-360.

[38] C. Turquat, C. Muller, E. Nigrelli, C. Leroux, J.-L. Soubeyroux, G. Nihoul, Eur. Phys. J. AP 10 (2000) 15-27.

[39] H. Kirchner, K. Merz, W. Brown, J. Am. Ceram. Soc. 46 (1963) 137-141.

[40] K. M. White, P. L. Lee, P. J. Chupas, K. W. Chapman, E. A. Payzant, A. C. Jupe, W. A. Bassett, C. S. Zha, A. P. Wilkinson, Chem. Mater. 20 (11) (2008) 3728-3734.

[41] T. Ota, I. Yamai, J. Mater. Sci. 22 (1987) 3762-3764.

[42] D. Craig, F. Hummel, J. Am. Ceram. Soc. 55 (1972) 532.

[43] J. Evans, J. Hanson, A. Sleight, Acta Cryst. B54 (1998) 705713.

[44] R. L. Withers, J. S. O. Evans, J. Hanson, A. W. Sleight, J. Solid State Chem. 137 (1998) 161-167.

[45] Y. Yamamura, A. Horikoshi, S. Yasuzuka, H. Saitoh, K. Saito, Dalton Trans. 40 (10) (2011) 2242-2248.

[46] S. Carlson, A. Krogh Andersen, J. Appl. Cryst. 34 (2001) 7-12.

[47] T. Sakuntala, A. K. Arora, V. Sivasubramanian, R. Rao, S. Kalavathi, S. K. Deb, Phys. Rev. B 75 (17) (2007) 174119.

[48] J. D. Jorgensen, Z. Hu, S. Teslic, D. N. Argyriou, S. Short, J. S. O. Evans, A. W. Sleight, Phys. Rev. B 59 (1999) 215-225.

[49] J. D. Jorgensen, Z. Hu, S. Short, A. W. Sleight, J. Evans, J. Appl. Phys. 89 (2001) 3184-3188.

[50] A. P. Wilkinson, C. R. Morelock, B. K. Greve, A. C. Jupe, K. W. Chapman, P. J. Chupas, C. Kurtz, J. Appl. Crystallogr. 44 (5) (2011) 1047-1053.

[51] A. Larson, R. Von Dreele, GSAS - General Structure Analysis System, Report LA-UR-86-748, Los Alamos Laboratory, 1987.

[52] S. Vogel, J. Appl. Crystallogr. 44 (4) (2011) 873-877.

[53] B. H. Toby, J. Appl. Crystallogr. 34 (2001) 210-213.

[54] G. Jennings, QXRD - Readout Software for Flat Panel X-Ray Detectors (unpublished).

[55] A. Hammersley, FIT2D: An Introduction and Overview, Tech. rep., ESRF (1997).

[56] G. A. Samara, T. Sakudo, K. Yoshimitsu, Phys. Rev. Lett. 35 (26) (1975) 1767-1769.
[57] D. A. McQuarrie, J. D. Simon, University Science Books, Sausalito, California, 1997.

[58] D. L. Decker, J. Appl. Phys. 36 (1965) 157-161.

[59] K. Brister, Rev. Sci. Inst. 68 (1997) 1629-1647.

[60] O. Anderson, Equations of state of solids for geophysics and ceramic science, Oxford University Press, Oxford, 1995.

[61] L. A. Girifalco, Statistical mechanics of solids, Vol. 58, Oxford University Press, 2003.

[62] J. Garai, A. Laugier, J. Appl. Phys. 101 (2) (2007) 023514. 

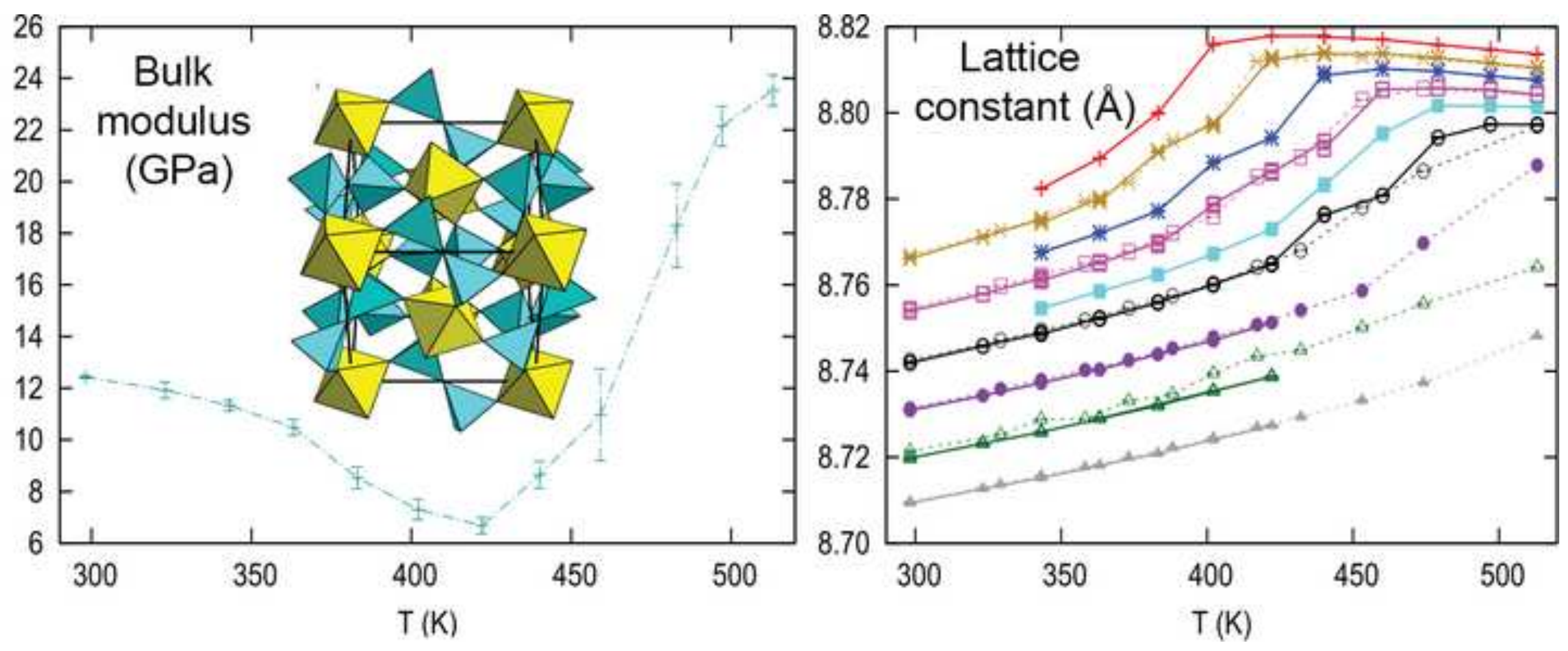
The temperature at which $\mathrm{ZrV}_{2} \mathrm{O}_{7}$ transforms to a phase displaying negative thermal expansion is strongly pressure dependent. The high temperature form of $\mathrm{ZrV}_{2} \mathrm{O}_{7}$ is elastically stiffer than the low temperature form. 